\title{
On-table urethral catheterisation during laparoscopic appendicectomy: Is it necessary?
}

\author{
Gregory J. Nason, MD; Sher N. Baig, MD; Matthew J. Burke, MD; Asadullah Aslam, MD; Michael E. Kelly, MD; \\ Leon G. Walsh, MD; Hugh D. Flood, MD; Subhasis K. Giri, MD
}

Department of Urology, University Hospital Limerick, Limerick, Ireland

Cite as: Can Urol Assoc J 2015;9(1-2):55-8. hittp://dx.doi.org/10.5489/cuaj.2341

Published online February 5, 2015.

\section{Abstract}

Introduction: Laparoscopic appendicectomy (LA) is the most commonly performed surgical emergency procedure. The aim of this study was to highlight a series of iatrogenic bladder injuries during LA and suggest a simple method of prevention.

Methods: A retrospective review was carried out of all LA performed in a university teaching hospital over a two year period 2012-2013. latrogenic visceral injuries were identified and operative notes examined.

Results: During the study period 1124 appendicectomies were performed. Four iatrogenic bladder injuries occurred related to secondary trocar insertion. No patient was catheterised preoperatively. One of the injuries was identified intra-operatively, another in the early postoperative period where as two re-presented acutely unwell post-discharge from hospital. Three were repaired by laparotomy and one laparoscopically.

Conclusion: latrogenic secondary trocar induced bladder injuries are a rare but preventable and potentially serious complication of LA. Urethral catheterisation during LA is a safe and simple method which can prevent this complication.

\section{Introduction}

Appendicectomy is the most common emergency surgical procedure performed worldwide. ${ }^{1}$ Laparoscopy plays a valuable role in the management of patients with acute lower abdominal pain. A Cochrane review has recommended laparoscopy and laparoscopic appendicectomy (LA) in patients with suspected appendicitis unless laparoscopy itself is contraindicated or not feasible. ${ }^{2}$ Minimally-invasive approaches have revolutionized surgery. ${ }^{3}$ Laparoscopic surgery has well-documented benefits with associated shorter length of stay, quicker return of bowel function, decreased analgesic requirements, lower rates of wound complications, and improved cosmesis. ${ }^{4,5}$ Furthermore LA is seen as an excellent training opportunity and evidence shows an attainable learning curve. ${ }^{6} \mathrm{LA}$ is a safe procedure for junior trainees to perform; ${ }^{7-9}$ however resident involvement in LA has resulted in increased operative time and complications. ${ }^{10,11}$

The overall rate of major complications following a laparoscopic procedure is about 1.4 per 1000 procedures. ${ }^{12}$ However, the incidence of port site complications following laparoscopic surgery is around 21 per 100000 cases. ${ }^{13}$ Port site complications can be grouped into access-related complications (vascular or visceral injuries) ${ }^{14}$ and postoperative complications (wound infection or port site herniation). ${ }^{15,16}$

Currently, there is little data regarding iatrogenic secondary trocar induced injuries in LA. The aim of this study was to highlight a series of iatrogenic bladder injuries during LA and suggest a simple method of prevention.

\section{Methods}

We performed a retrospective analysis of LA over a 2-year period (2012-2013) at a tertiary referral university teaching hospital. Data were obtained from the hospital in-patient enquiry (HIPE) system. The outcomes measured included the incidence of iatrogenic bladder injuries at the time of LA, mode and time of clinical presentation, type of port used, level of surgeon experience, type of bladder repair, length of stay after repair, and final outcome.

\section{Procedure}

All patients were requested to empty their bladder prior to coming to operation theatre as per local protocol. Although there were minor variations in peritoneal access and port placement among operating surgeons, the operative techniques were standard. Prophylactic antibiotics were routinely administered at induction and continued for 24 hours. The patients were positioned supine on the operating table with 
arms abducted at $90^{\circ}$ and the table tilted to Trendelenburg's position. The monitors were placed at the right side of the bed, with surgeons and assistant standing on the left. The Hasson technique (open laparoscopy) was used to insert a 10-mm camera port (primary port) at the umbilicus. Two working (secondary) ports were then inserted under direct laparoscopic vision at the following locations: 5-mm port $1 \mathrm{~cm}$ medial to the anterior superior iliac spine and a 10-mm port $1 \mathrm{~cm}$ above the pubic symphysis in the midline for better cosmetic outcome. Placement of trocar was at the discretion of the operating surgeon.

Full laparoscopic exploration of the abdomen was always performed and the small bowel was inspected. The appendix was identified and manipulated with atraumatic graspers, allowing division of the meso-appendix with electrocautery. The appendix base was ligated with Endo Loop ligatures (Ethicon Endo-Surgery, Cincinnati, $\mathrm{OH}$ ) prior to transection, allowing its removal in an Endo Catch through the 10-mm port. Drains were not routinely used.

Patients were discharged once comfortable, were able to tolerate oral analgesia and diet - usually 24 to 48 hours postoperatively. All patients were reviewed at the outpatient clinic 6 to 8 weeks following discharge.

This retrospective chart review was approved at the local research meeting.

\section{Results}

During the study period 1124 appendicectomies were performed, 894 (79.5\%) were completed laparoscopically. Four iatrogenic bladder injuries occurred related to secondary trocar insertion $(0.36 \%$ of all LA). There were no other visceral or major vascular injuries. None of the patients had a history of lower abdominal surgery. Three of the LAs were performed outside of normal working hours; however, a consultant was present for each case.

\section{Case 1}

A 22-year-old male patient presented to the emergency department 4 days post-discharge following a LA with fever, abdominal pain, distension, and oliguria. Biochemical analysis revealed acute renal failure. Computed tomography revealed clot and air within the bladder suggestive of a bladder perforation. He underwent a laparotomy and repair of a defect in the dome of the bladder in 2 layers in a water-tight fashion using absorbable polyglactin. He was discharged 4 days later and a urethral catheter was left in place for 2 weeks. He reported some difficulty urinating prior to discharge following LA. However as his post-void bladder scan did not reveal significant residual urine and he was comfortable oral analgesia, he was discharged.

\section{Case 2}

A 12-year-old boy reported frank hematuria 1 day after LA. A renal ultrasound demonstrated mild hydronephrosis and suggested a blood clot within the urinary bladder. Rigid cystoscopy under general anesthesia demonstrated a mucosal tear on the anterior bladder wall. Laparoscopy revealed free fluid in the recto-vesical pouch and para-colic gutters. A 1-cm defect was noted in the anterior bladder wall near the dome of the bladder. The defect was closed in 2 layers using a V-Lock (breaded polyglactin) suture. A leak test demonstrated water-tight closure of the bladder perforation. A urinary catheter was left in situ for 2 days. He was discharged 4 days after the LA.

\section{Case 3}

A 70-year-old male presented to the emergency department feeling unwell 2 days post-discharge following LA. He complained of vomiting, abdominal pain, and an inability to void urine. On presentation, a urethral catheter was inserted and drained $300 \mathrm{ml}$ of urine; however, this failed to resolve his discomfort. Computed tomography revealed free fluid in the abdomen and free air in the abdomen and bladder. An exploratory laparotomy demonstrated a defect in the dome of the bladder which was closed in 2 layers using absorbable sutures. A urinary catheter was left in place for 2 weeks. He was discharged 6 days following exploratory laparotomy. He reported some difficulty urinating following LA prior to his discharge and once again, as his post-void bladder scan did not reveal significant residual urine and he was comfortable on oral analgesics, he was discharged.

\section{Case 4}

A 30-year-old male was undergoing a LA when an iatrogenic bladder injury was identified. The injury occurred at insertion of the supra-pubic secondary port. The urologist on-call was contacted and a laparotomy was performed and the bladder defect was closed in 2 layers using absorbable polyglactin suture. A urinary catheter was left in place for 5 days postoperatively. He was discharged 5 days after the LA.

All patients were followed up independently 8 weeks postoperatively in both the general surgical and urology out-patient clinics. Histology revealed acute appendicitis in all cases. All had successful trials of micturition following removal of urethral catheter and no patient reported subsequent voiding difficulties.

\section{Discussion}

This study highlights the risk of secondary trocar induced iatrogenic bladder injuries during laparoscopic appendicec- 
tomy. The incidence of bladder injury was $0.36 \%$. Although the incidence was low, our study serves as a stark reminder of the potentially serious and preventable complication of iatrogenic bladder injury during insertion of secondary (working) trocar during LA.

Acute abdominal pain and suspected appendicitis are the most common causes of emergency surgical admissions. An accurate preoperative diagnosis at times can be extremely difficult. Although imaging modalities, such as computed tomography, may help in the diagnosis, they are not always readily available to emergency clinicians, especially outside of regular office hours. ${ }^{17}$ Thus appendicectomy remains the most frequently performed operation by residents and often performed outside normal working hours. ${ }^{18}$ LA is generally accepted as a safe procedure and included as part of a general surgical curriculum. ${ }^{7,19}$ In a large national review of LA, Advani and colleagues demonstrated that resident involvement resulted in increased operative times and significant increase in complications, regardless of their year in postgraduate training. ${ }^{10}$ Emergency cases performed "out of hours" are associated with increased risk of morbidity. ${ }^{20,21}$ Deferring appendicectomy for 12 to 24 hours so that it can be performed during daytime working hours does not increase rates of perforations or overall length of stay. ${ }^{22,23}$ In an effort to provide a cost-effective service, there has been recent centralization of surgical services in our region - the introduction of a surgical assessment unit, a "surgeon of the week," and a full-time emergency theatre with resultant gradual shift towards daytime operating. ${ }^{24}$ However, this has not reduced the rate of negative appendicectomy and the risk of trocar-induced bladder injuries continues.

Debate remains regarding urethral catheterization prior to laparoscopic surgery. Although Levy and colleagues reported only $0.36 \%(6 / 1671)$ of iatrogenic bladder injuries due to laparoscopic secondary port insertions in patients without prior history of abdominal surgery, one of their young patients developed a horrendous complication - gangrene of the abdominal wall (necrotising fasciitis). ${ }^{25}$ The authors took into account all the laparoscopic cases (diagnostic and therapeutic), but failed to mention the study period. All but one of these patients underwent temporary preoperative in/out catheterization before surgery. It was not clear from the study the exact time of catheterization with regard to operative procedure. Thus it is possible that the bladder had refilled between the in/out catheter and insertion of supra-pubic secondary trocar. On-table urethral catheterization and maintaining free drainage of urine during the laparoscopic procedure are likely to avoid these potentially preventable but serious consequences (clinical and medico-legal).

In a randomized, double blinded control trial $(n=262)$, Tang and colleagues reported that during elective laparoscopic gynaecological surgery only $4 \%$ of their non-catheterized group required urinary catheterization mid-procedure and no bladder injuries occurred. ${ }^{26}$ The authors have suggested the identification of bladder margins intra-operatively and insertion of urethral catheter mid-procedure if necessary. In the emergency setting, such steps are likely to be inconvenient. In our series, a consultant surgeon was consulted in all the cases of iatrogenic bladder injuries. This emphasizes the difficulty in identifying partially filled bladder during laparoscopy. The French College of Gynaecologists and Obstetricians recommend draining the urinary bladder prior to insertions of trocars. ${ }^{27}$

The prophylactic use of a bladder ultrasound scanner has been postulated previously. Greig and colleagues demonstrated that voiding immediately preoperatively does not guarantee bladder emptying; $13 \%$ of these patients required catheterization due to post-void residuals greater than $300 \mathrm{~mL} .^{28}$ Moselhi and colleagues described the use of a portable ultrasound to assess the volume in the bladder immediately prior to laparoscopic gynaecology surgery; catheterization was performed if the estimated volume was greater than $100 \mathrm{~mL} .{ }^{29}$ However, the availability of an ultrasound scanner and a trainee competent in ultrasonography were likely to limit its routine use.

There is a lack of data on laparoscopic trocar insertion injuries at LA. Our study highlights the considerable clinical morbidity resulting from iatrogenic bladder injuries at LA in acutely unwell patients. These patients required prolonged urethral catheterization; 2 patients were discharged with catheters in-situ causing additional discomfort. Furthermore, this potentially preventable injury increases the length of stay in our already strained health service. A further non-clinical implication was the potential medico-legal issues associated with a preventable iatrogenic injury - this was not explored in this study.

Many institutions adopt policies requesting patients to empty their bladder immediately prior to surgery. However this method is clearly inadequate as reflected in our study. One possible explanation is the fact that patients, who are already in pain due to their appendicitis, are unable to completely void. Kashefi and colleagues reported a minor urethral injury incidence rate of $0.007 \%$ following male catheterization after a catheter education program, ${ }^{30}$ highlighting the relative ease and safety of urethral catheterization. We feel that on-table urethral catheterization and maintaining free drainage of urine during the laparoscopic procedure are simple and safe ways to avert serious bladder injuries. This should be standard practice irrespective of surgeon experience.

Our study has limitations. This was a retrospective, small series, but this does highlight the seriousness of the issue. If one can avoid a surgical complication, even if it is rare, we should adopt a safer technique. 


\section{Conclusion}

latrogenic secondary trocar induced bladder injuries are a rare but preventable and potentially serious complication of laparoscopic appendicectomy. On-table urethral catheterization and maintaining continuous free drainage of urine during LA are safe and simple ways to prevent complications regardless of surgeon experience.

Competing interests: Authors declare no competing financial or personal interests.

This paper has been peer-reviewed.

\section{References}

1. Addiss DG, Shaffer N, Fowler BS, et al. The epidemiology of appendicitis and appendectomy in the United States. Am J Epidemiol 1990;132:910-25.

2. Sauerland S, Jaschinski T, Neugebauer EA. Laparoscopic versus open surgery for suspected appendicitis. Cochrane Database Syst Rev 2010:CD001546.

3. Karthik S, Augustine AJ, Shibumon MM, et al. Analysis of laparoscopic port site complications: A descriptive study. J Minim Access Surg 2013;9:59-64. http://dx.doi.org/10.4103/0972-9941.110964

4. Marohn MR, Hanly EJ, McKenna KJ, et al. Laparoscopic total abdominal colectomy in the acute setting. J Gastrointest Surg 2005;9:881-6; discussion 887. http://dx.doi.org/10.1016/i.gassur.2005.04.017

5. Rosman AS, Melis M, Fichera A. Meta-analysis of trials comparing laparoscopic and open surgery for Crohn's disease. Surg Endosc 2005;19:1549-55. http://dx.doi.org/10.1007/s00464-005-0114-9

6. Kim SY, Hong SG, Roh HR, et al. Learning curve for a laparoscopic appendectomy by a surgical trainee. J Korean Soc Coloproctol 2010;26:324-8. http://dx.doi.org/10.3393/iksc.2010.26.5.324

7. Jaffer U, Cameron AE. Laparoscopic appendectomy: A junior trainee's learning curve. ISLS 2008; 12:28891.

8. Naiditch JA, Lautz TB, Raval MV, et al. Effect of resident postgraduate year on outcomes after laparoscopic appendectomy for appendicitis in children. J Laparoendosc Adv Surg Tech A 2012;22:715-9. http:// dx.doi.org/10.1089/lap.2012.0032

9. Perry ZH, Netz U, Mizrahi S, et al. Laparoscopic appendectomy as an initial step in independent laparoscopic surgery by surgical residents. J Laparoendosc Adv Surg Tech A 2010;20:447-50. http://dx.doi. org/10.1089/lap.2009.0430

10. Advani V, Ahad S, Gonczy C, et al. Does resident involvement effect surgical times and complication rates during laparoscopic appendectomy for uncomplicated appendicitis? An analysis of 16,849 cases from the ACS-NSQIP. Am J Surg 2012;203:347-51; discussion 351-2. http://dx.doi.org/10.1016/i. amisurg.2011.08.015

11. Papandria $D$, Rhee $D$, Ortega $G$, et al. Assessing trainee impact on operative time for common general surgical procedures in ACS-NSQIP. J Surg Educ 2012;69:149-55. http://dx.doi.org/10.1016/i. isurg.2011.08.003

12. Jansen FW, Kapiteyn K, Trimbos-Kemper T, et al. Complications of laparoscopy a prospective multicentre observational study. Br J Obstet Gynaecol 1997;104:595-600. http://dx.doi. org/10.1111/j.1471-0528.1997.tb11539.x

13. Aziz R. Practical manual of operative laparoscopy. New York: Springer-Verlag; 1992:1-8. http://dx.doi. org/10.1007/978-1-4684-0430-2_1
14. Mayol J, Garcia-Aguilar J, Oritiz-Oshiro E, et al. Risks of the minimal access approach for laparoscopic surgery: Multivariate analysis of morbidity related to umbilical trocar insertion. World J Surg 1997;21:52933. http://dx.doi.org/10.1007/PL00012281

15. Richards C, Edwards J, Culver D, et al. The National nosocomial infections surveillance (NNIS) system, centers for disease control and prevention. Does using a laparoscopic approach to cholecystectomy decrease the risk of surgical site infection? Ann Surg 2003;237:358-62. http://dx.doi.org/10.1097/01. SLA.0000055221.50062.7A

16. Targarona EM, Balagué $C$, Knook MM, et al. Laparoscopic surgery and surgical infection. Br I Surg 2000;87:536-44. http://dx.doi.org/10.1046/i.1365-2168.2000.01429.x

17. Giri SK, Shaikh FM, Sil D, et al. Our experience with selective laparoscopy through an open appendectomy incision in the management of suspected appendicitis. Am J Surg 2007;194:231-3. http://dx.doi. org/10.1016/i.amisurg.2006.10.030

18. Yaghoubian A, Kaii AH, Ishaque B, et al. Acute care surgery performed by sleep deprived residents: Are outcomes affected? I Surg Res 2010;163:192-6. http://dx.doi.org/10.1016/i.js.2010.04.011

19. Neugebauer E, Troidl H, Kum CK, et al. The E.A.E.S. consensus development conferences on laparoscopic cholecystectomy, appendectomy, and hernia repair. Consensus statements-September 1994. The Educational Committee of the European Association for Endoscopic Surgery. Surg Endosc 1995;9:550-63.

20. Kelz RR, Freeman KM, Hosokawa PW, et al. Time of day is associated with postoperative morbidity: An analysis of the national surgical quality improvement program data. Ann Surg 2008;247:544-52. http:// dx.doi.org/10.1097/SLA.0b013e31815d7434

21. Kelz RR, Tran TT, Hosokawa P, et al. Time-of-day effects on surgical outcomes in the private sector: A retrospective cohort study. J Am Coll Surg 2009;209:434-445.e2

22. Abou-Nukta F, Bakhos C, Arroyo K, et al. Effects of delaying appendectomy for acute appendicitis for 12 to 24 hours. Arch Surg 2006;141:504-6; discussion 506-7. http://dx.doi.org/10.1001/archsurg. 141.5 .504

23. Yardeni $D$, Hirschl RB, Drongowski RA, et al. Delayed versus immediate surgery in acute appendicitis: Do we need to operate during the night? J Pediatr Surg 2004;39:464-9; discussion 464-9. http://dx.doi. org/10.1016/i.jpedsurg.2003.11.020

24. Healy DA, McCartan DP, Grace PA, et al. The impact of regional reconfiguration on the management of appendicitis. Ir J Med Sci 2014;183:351-5. Epub 2013 0ct 4. http://dx.doi.org/10.1007/s11845013-1015- $x$

25. Levy BF, De Guara J, Willson PD, et al. Bladder injuries in emergency/expedited laparoscopic surgery in the absence of previous surgery: A case series. Ann R Coll Surg Engl 2012;94:el 18-20. http://dx.doi. org/10.1308/003588412X13171221502149

26. Tang KK, Wong CK, Lo SF, et al. Is it necessary to catheterise the bladder routinely before gynaecological laparoscopic surgery? Aust N Z J Obstet Gynaecol 2005;45:380-3. http://dx.doi.org/10.1111/j.1479828X.2005.00443.X

27. Deffieux X, Ballester M, Collinet $P$, et al. Risks associated with laparoscopic entry: Guidelines for clinical practice from the French College of Gynaecologists and Obstetricians. Eur J Obstet Gynecol Reprod Biol 2011;158:159-66. http://dx.doi.org/10.1016/i.ejogrb.2011.04.047

28. Greig JD, Mahadaven M, John TG, et al. Comparison of manual and ultrasonographic evaluation of bladder size in patients prior to laparoscopy. Surg Endosc 1996;10:432-3. http://dx.doi.org/10.1007/ BF00191633

29. Moselhi M, Morgan M. Use of a portable bladder scanner to reduce the incidence of bladder catheterisation prior to laparoscopy. BJOG 2001;108:423-4. http://dx.doi.org/10.1111/j.1471-0528.2001.00101.x

30. Kashefi C, Messer K, Barden R, et al. Incidence and prevention of iatrogenic urethral injuries. J Urol 2008;179:2254-7. http://dx.doi.org/10.1016/i.juro.2008.01.108

Correspondence: Mr Gregory Nason, Specialist Registrar in Urology, University Hospital Limerick, Dooradoyle, Limerick, Ireland; nasong@tcd.ie 